\title{
Strategic Human Resource Development in Hospitality Crisis Management: A Conceptual Framework for Food and Beverage Departments
}

\author{
Ala`a Nimer AbuKhalifeh \\ School of Housing, Building and Planning, Universiti Sains Malaysia, Malaysia \\ E-mail: ana11_hbp046@student.usm.my \\ Ahmad Puad Mat Som \\ School of Housing, Building and Planning, Universiti Sains Malaysia \\ \& Sustainable Tourism Research Cluster (STRC), Universiti Sains Malaysia, Malaysia \\ E-mail: puad@usm.my \\ Ahmad Rasmi AlBattat \\ School of Housing, Building and Planning, Universiti Sains Malaysia, Malaysia \\ E-mail: battat_ahmed@yahoo.com
}

Received: October 24, $2012 \quad$ Accepted: December 20, $2012 \quad$ Online Published: January 5, 2013

doi:10.5430/ijba.v4n1p39 URL: http://dx.doi.org/10.5430/ijba.v4n1p39

\begin{abstract}
Crisis management has been a largely unnoticed territory in human resource development. Despite the increased impact of organizational crises on individual and organizational performance, it remains to be an issue that must be recognized and addressed. This paper reviews the current literature on hotel industry crisis management, its progression and effective crisis management framework. Garavan`s strategic human resource model as a guiding framework is discussed to help understand the various ways in which human resource development can build crisis management capabilities in organizations. The study applies various components of the model to the crisis management context and integrates ideas from the literatures. The paper offers specific guidelines for practitioners regarding how to align strategic human resource development with food and beverage department strategies and identify areas for future research.
\end{abstract}

Keywords: Crisis management, Hotel industry, Strategic human resource development, Food and beverage, Malaysia

\section{Introduction}

Many researchers have examined the existing crises in organizational settings (Ghaderi, Mat Som \& Henderson, 2012; Gilley \& Eggland, 1989; Gilley \& Maycunich, 2000; Pauchant \& Mitroff, 1992; Pearson \& Clair, 1998; Reilly, 1987; Sayegh, Anthony, \& Perrewe, 2004; Turner, 1976; Wang, Hutchins, and Garavan, 2009). Literature has suggested some level of agreement on the nature of organizational crisis and the range of organizational crisis management. Agreeing on the definition of a crisis has a proven challenging or a crisis theorist and practitioners. This may possibly symbolize the changing nature of crisis events during the last decade (Wang et al., 2009). Financial, social, industrial, health, and economic crises are terms often used to identify undesirable and sometimes unlikely events that have significant impacts. Despite the vibrations, a crisis is typically recognized as a low probability. High impact situations are unforeseen, unfamiliar, and precipitated by people, organizational structures, economics, technology or natural disasters (Pearson \& Clair, 1998; Reilly, 1987). Crisis events can be instantaneous or slow to emerge or "creeping", similar to the environmental crisis or the more recent energy surge that has resulted in a gradual increase in fuel costs for most countries (Sayegh et al., 2004). Synthesizing the literature and acknowledging six main characteristics of an organizational crisis, include the following : (1) high ambiguity with 
unknown causes and effects, (2) a low probability of it occurring, (3) an unusual and unfamiliar event, (4) the requirement for a rapid response, (5) a significant threat to the survival of the organization and stakeholders, and (6) the need for a quick decision that potentially has positive or negative effects (Wang et al., 2009).

Being prepared for such mission, Smith (1990) indicated that organizations need to ensure that they have suitable frameworks and potentialities to handle crises events. In addition, it is becoming fundamentally important for hotels to give grave consideration to the management issues in triggering crises. The degree to which a hotel is successful in managing and handling a crisis in the food and beverage departments is hinged on their proactive responses and preparedness which should have been highlighted in their long - term crisis management plan. It is essential to recognize that most prepared hotels provide basic but continuous investigation in auditing their decisions. Their management structures will then be constantly on guard for probable errors and obstacles before it becomes too late for a simple solution (Pearson \& Mitroff, 1993). However, ill-preparedness in the hotels for emergencies will subject themselves to the high risk of losing their resources which lead to business failure.

While the significance of re-scrutinizing the previous act of those concerned in retrospect, it imperative to understand the intervals between crises decrease at alarming rates. A momentary look at the news headlines show that a number of crises terminating billion-dollar losses have increased radically in the past decade. Crises are happening more often and they have become almost a daily lot of guests ' places. In this sense, experienced managers to ambivalently neglect or disregard crisis preparation will prevent the adoption of hotel crisis management (Parsons \& Clair, 1989). An outline attention to this fact, Mitroff, Shariastava \& Udwadia (1987:291) emphasized " For those who work in the field of crisis management, it is no longer question of whether a major crisis will strike any organization, but only a matter of when, who, what, form will it take and who and how many will be affected?'

This paper provides a theoretical overview of the Garavan`s model for human resource development in hospitality crises management. The purpose of this study is to explain that the application of the model can either determine the human resource development which can lead to effective crises plan in the food and beverage department. A strategic application of human resource development in a crisis management framework is proposed to the Malaysian hotel industry, and this will act as a guideline to handle catastrophic incidents more effectively. Lack of studies in local context provides an opportunity to enrich literature review in this field.

\section{Literature Review}

\subsection{A Review of Human Resource Development, Crisis Management Procedures and Models}

Given this fact that the increase in frequency and complexity of hotel crises, the need for a planned effort to alleviate crisis events has become a serious concern for the hotels (Wang et al., 2009). It is necessary to learn quickly from crisis events that actually occur. Hotels` crisis management is understood as a series of procedures used to sustain or renew usual business operations, minimize stakeholders loss, and use learning to improve the crisis management process (Pearson \& Clair, 1998). Crisis management naturally includes steps that help to identify potential crisis signals or indicators, planning strategies, response coordination, and recovery plans. To facilitate this process, several authors have recommended various procedures for effective hotel management crisis. Heath (1998) spotted that western organizations have typically adopted a four stage model: prevention, preparation, response, and recovery. He viewed this model as interactive with opportunities for ongoing learning as considered an axiom and a critical recurrent feature of the majority of crisis management models.

Among several models of crisis management, the one initially proposed by Pearson \& Mitroff (1993) and later refined by Mitroff (2005) appeared to be the most comprehensive and representative of earlier and more current model articulations. McConnell \& Drennan (2006) explained that hotels fail to engage in crisis management because they lack an understanding of how to connect in systematic planning across often fragmented units. Consequently, an organization would rather place resources toward more instant profit generating needs and is overwhelmed by the absolute number of probable crisis events that could occur. Another impediment to crisis planning is the cultural belief system, often communicated by senior executives, concerning the extent of crisis management efforts, this is supported by Mitroff (1988), Pauchant \& Mitroff (1992), Pearson \& Clair (1998), Turner (1976).

There are several developed crisis management models shown in the literature by researchers such as by Garavan (1991, 2007), Garavan, Costine \& Heraty (1995), Gilley and Eggland (1989), McCracken \& Wallace (2000), Horwitz (1999), Brewton (1987), Faulkner (2001), Racherla \& Hu (2009), Yorks (2005), Smith (1990). Applicable to the hotel industry, Garavan`s work of crisis management has been recognized as one of the most appropriate or comprehensive and integrated analysis of crisis management in the food and beverage department (Pforr \& Hosie, 2008; Wang et al., 2009). Many studies have employed this model in different hotel crisis situations. For example, 
Garavan (2007) and Wang et al. (2009) reiterated Garavan's model for strategic human resource development (SHRD) in organizational crisis management plans by examining three major constructs. The focus of their study was on how the strategic role of human resource development can cope with crisis management.

Wang et al. (2009) examined Garavan's model in strategic human resource in organizational crisis management. In this study, the authors will focus on Garavan`s model on crisis management within the context of the hotel industry in Malaysia. The great benefit of this framework is incorporating the four levels of context which shaped the SHRD activities of various models into a refined model of crisis management in an F\&B department. As Wang et al. (2009) stated, "In subsequent sections, we apply Garavan`s (2007) SHRD model to arrange of crisis management activities and examine SHRD's contribution at four levels of analysis: organizational, team, job, and individual. They conclude with a discussion of the implications of the analysis for organizational practice and future research". This generic model is extensively applicable to a variety of crisis management situations ranging from the enterprise level to the F\&B department management stage.

\section{Garavan`s Strategic Human Resource Model and Its Application to Food and Beverage}

Garavan's model follows the three major constructs: the context, the human resource development, and the stockholders. According to Garavan, four levels of context shape the SHRD activities: the global context (Level 1), the organizational context including strategy, structure, culture, and leadership (Level 2), the job (Level 3), and the individual (Level 4). The model outlines three characteristics of the SHRD focused for orientation and strategies. Moreover, the model acknowledges the importance of multiple stakeholders that have emerged in the design, development, and implementation of the SHRD. These are jointly internal and external to the organization such as owners, employers, employees, suppliers, and customers. The model emphasized horizontal and vertical linkages throughout and suggests many stakeholders - focused outcomes. These stakeholders react to and evaluate outcomes, as well as offer input into the SHRD process. Garavan's framework is used to direct our exploration of the role of SHRD in the specific context of hotels' crisis management in the F\&B department. Each pictorial component in Garavan's model will be elaborated in the following two sections. The model is a generalized one that prescribes the issues that are relevant at each level (Wang et al., 2009). It does not concentrate on the implementation procedures or how crisis management is enacted or managed in exacting situations.

Due to the lack of an integrated and comprehensive model for hotel crisis management, this paper suggests the application of Garavan's (2007) framework of food and beverage management crisis in designing an effective crisis plan process in the Malaysian context. This framework will help the hotel management and industry players to prepare themselves for future grievous events. It also hopes to improve an F\&B service department's ability to identify, analyze, control and manage a broad spectrum of potential food crisis. At the same time, the process will fulfill the hotel's strategic role to ensure resilience and the survival of hotels.

$<$ Insert Figure 1 Here $>$

\subsection{Level (1): The Global Context}

Level (1) of the model focuses on a multiplicity of external factors that shape the role of SHRD in crisis management and trigger particular SHRD initiatives. Local or national conditions may focus on laws. For example, many inflict binding obligations on organizations to develop contingency plans and provide a variety of forms for crisis management training. Health and safety laws may require hotels to advise emergency planning processes to address potential crises. There is a strong focus on national laws on attentiveness. Some national governments do not adopt the "hard" laws approach; rather focus on "soft" intervention such as codes and protocols. There are typically written documents that do not have any legal impact, but there is consensus that certain practices should be followed. They may be formulated by government agencies and political authorities or they may be advocated by employer bodies or associations or trade unions or hotel management. They are also known to protrude as a component of partnership arrangements between the government, employers, and trade unions (Wang et al., 2009).

\subsection{Level (2): Strategy, Structure, Culture, and Leadership}

The hotels internal context shapes and explains the contribution of the SHRD to crisis management efforts. Particular dimensions of the internal context that are pertinent include the hotels`strategy, structure, culture and leadership. The strategic orientation of the hotels has significance in explaining the spotlight and types of SHRD practices that are introduced to management crisis events. The organizational hotel context is also necessary in explaining the resources that are committed to crisis management activities. Furthermore, various aspects of the hotel management organizational structure are applicable in shaping crisis efforts and the contribution that SHRD can make. Hillyard (2000) highlighted that crisis management needs to illustrate on compound sources of proficiency across a range of 
networks. The structural dynamics may result in many conflicting tendencies such as centralization versus fragmentation. A key challenge is to ensure that the goals and strategies of crisis management are associated with each other. Horizontal alignment focuses on the extent to which SHRD activities elicit appropriate structural behavior. On the other hand, SHRD can subscribe to effective horizontal alignment through leadership development activities, the development of commitment to crisis management, skills training, and empowerment strategies (Wang et al., 2009).

Structural considerations have a main implication for the use of knowledge about crises and the way in which they are integrated into policy and the wider concept of organizational learning (Garavan, 2007; Wang et al., 2009). Elliott (2006) and Smith (1995) recommended that structural or confirmation features of hotels`organization may inhabit the learning practices and make a situation where beliefs are reinforced rather than challenged. They further explained that from the crisis management perspective, it is necessary to examine the manner in which decisions are made and how structures and cultures framed that process. For example, a reputable international hotel chain located in the Mediterranean discovered a major food poisoning outbreak that affected thousands of customers. The response was quick and decisive. The hotel management executive team immediately activated their crisis management plan in the food and beverage service department that included engaging repeated guests (Paraskevas, 2006; Wang et al., 2009). Some of the properties had more infected guests than others but the coordination between properties had not been part of the crisis plan. With minimal training and little experience, the supervisors were left not knowing how to handle such a crisis in some properties. In reflection, the crisis plan should have been clarified from both a vertical and horizontal perspective which would have allowed resources and support to be shared between the properties.

Organizational culture lies in the heart of crisis management. Pauchant \& Mitroff (1992) argued that concepts such as proneness and resistance to the crisis were visible in the form of organizational practices, routines, and structures. These characteristics were largely determined by collective and individual beliefs. They suggested that crisis prone organizations have institutionalized "sickness" in their culture, thus making it acceptable; furthermore, they put tremendous pressure on the normal individual to become "sick to fit in" (pp.172-173). Such a cultural context requires SHRD interventions that can challenge the paradigm while making it safe to critically evaluate decisions and actions. Finally, organizational leadership is central to the implementation of crisis management initiatives and is highlighted as a main influence on SHRD. Effective leadership is critical to articulating the crisis management agenda (Wang et al., 2009), leaders confer legitimacy on both crisis management and SHRD. Boin \& Lagadec (2000) projected that crisis management was on the plan for decision making elites and that leader occupied continuous efforts of preparation. They suggested a number of ways in which leadership can connect with SHRD interventions in a crisis management context. These involved organizational leaders in training and development, promoting learning within and across networks, aligning crisis management efforts with the core values of the organizations, and continually learning from experience (Wang et al., 2009; Wooten \& James, 2008).

\subsection{Level (3): The Job Context}

Different levels of values and uniqueness of jobs (Garavan, 2007; Wang et al., 2009) may shape the responses of the SHRD to crisis management. Various job roles that are necessary in the context of crisis management (Bulmahn \& Krakel, 2002) insist that the most important tasks for key organizational hotels' leaders consist of focusing on information exchange to guaranteeing coherence before a crisis occurs and prepares for unknown crisis. Roberts \& Bea (2001) called for teams to be shaped to tackle difficult crisis management duties and to ensure appropriate design making. Poorly prepared and trained personnel will not be able to handle well a disaster or crisis. For example, a Mediterranean hotel executive team and the property managers had completed the simulations a month before the food contamination incident occurred. They later realized that the crisis plan had not been fully experienced or understood by all employees in the F\&B department. Mitroff \& Alpaslan (2003) contended that a significant component of crisis preparedness is to create an expert employee that will expect future crisis possibilities and correspond appropriate counter measures.

\subsection{Level (4): The Individual Context}

The final level is on the individual context. This includes expectations, attitudes, employability, and cognitive characteristics which can influence the types of SHRD activities in which hotel organizations may adopt in the context of crisis management. Many scholars such as Sayegh, Anthony \& Perrewe (2004), Lazar (1999), Grandey (2000) anticipated crisis management experiences that consists of education, training, and revealing crisis events. In addition, managers and employees need clear knowledge which facilitates the dissemination of information in a rational way and the capacity to analyze information in a truly stressful situation. The possession of strong 
self-efficacy has affected the employees' ability to standardize emotions and the confidence to make decisions in crisis situations.

\section{Conclusion}

In this study, the strategic human resource development for crisis management activities in the hospitality industry was discussed. A crisis model for food and beverage departments was suggested. With regard to the literature review, this study found a lack of resources with regard to the human resource crisis in the F\&B department in Malaysian hotels. It is suggested that a developed crises management plan in the hotel industry based on Garavan`s model be devised. It can generally be contested that four levels can explain Garavan's framework. First, the customers directly gain human resource development from the crisis management level: the global context, strategy, structure, culture, and leadership, the job context, the individual context. When they perceive a higher safety level, they will eventually turn to the crisis management plan of a specific service provided such as the F\&B department. Second, the hotel management and HRD may play an important role in the effectiveness of crises management and awareness. The application of this model by hotels can bring success for hotel management and F\&B employees to accomplish a crisis plan which has a direct effect on micro environments of organizational hotels. This paper is only conceptual where future studies may incorporate empirical data that will be collected from F\&B departments in selected hotels in Malaysia.

\section{Acknowledgement}

The authors would like to extend their appreciation to Universiti Sains Malaysia for the Research University's Grant under the Sustainable Tourism Research Cluster entitled 'Tourism Planning' [Grant No. 1001/PTS/8660013] and the university's fellowship scheme that help make this study and paper possible.

\section{References}

Boin, A., \& Lagadec, P. (2000). Preparing for the future: Critical challenges in crisis management. Journal of Contingencies and Crisis Management, 8, 185-191.

Brewton, C. (1987). Managing a Crisis: A Model for the Lodging Industry. Cornell Hotel and Restaurant Administration Quarterly 1, 12-15.

Bulmahn, G., \& Krakel, M. (2002). Over-educated workers as an insurance device. Labour: Review of Labour Economics and Industrial Relations, 16, 383-402.

Elliott, D. (2006). Crisis management into practice. In D. Smith \& D. Elliott (Eds.), Key readings in crisis management (pp. 393-414). New York: Routledge.

Faulkner, B. (2001). Towards a framework for tourism disaster management. Tourism Management Perspectives, 22, 135-147.

Garavan. (1991). Strategic human resource development. Journal of European Industrial Training, 15(1), 17-30.

Garavan. (2007). A strategic perspective on human resource development. Advances in Developing Human Resources, 9, 11-30.

Garavan, Costine, P., \& Heraty, N. T. (1995). The emergence of strategic human resource developmen. Journal of European Industrial Training, 19(10), 4-10.

Ghaderi, Z., Mat Som, A. P., \& Henderson, J. C. (2012). Case study:Tourism crises and island destinations:

Experiences in Penang, Malaysia. Tourism Management Perspectives, 2-3(2), $79-84$. http://dx.doi.org/10.1016/j.tmp.2012.03.006

Gilley, J., \& Eggland, S. A. (1989). Principles of human resource development.

Gilley, J., \& Maycunich, A. (2000). Organizational learning, performance and change: An introduction to strategic human resource development.

Grandey, A. (2000). Emotion regulation in the workplace: A new way to conceptualize emotional labour. Journal of Occupational Health Psychology, 5, 95-110.

Heath, R. (1998). Dealing with complete crisis-the crisis management shell structure. Safety Science, 30(1-2), $139-150$.

Hillyard, M. T. (2000). Public crisis management, how and why organisations work together to solve society's most threatening problems, C. W. P. C. San Jose (Ed.).

Horwitz, F. (1999). The emergence of strategic training and development: The current state of play. Journal of European Industrial Training, 23(4/5), 180-190. 
Lazar, A. (1999). Deceiving oneself or self-deceived? On the formation of beliefs "under the influence." Mind, 108, 265-290.

McConnell, A., \& Drennan, L. (2006). Mission impossible? Planning and preparing for crisis. Journal of Contingencies and Crisis Management, 4(59-70).

McCracken, M., \& Wallace, M. (2000). Towards a redefinition of strategic HRD. Journal of European Industrial Training, 24(5), 281-290.

Mitroff. (1988). Crisis management: Cutting through the confusion. Sloan Management Review, 29(2), 15-20.

Mitroff. (2005). Why some companies emerge stronger and better from a crisis: 7 essential lessons for surviving disaster.

Mitroff, \& Alpaslan, M. C. (2003). Preparing for evil. Harvard Business Review, 81(4), 109-115.

Mitroff, Shariastava, P., \& Udwadia, F. E. (1987). Effective Crisis Management. The Academy of Management Executive, Retrieved, 3, 291.

Paraskevas, A. (2006). Crisis management or crisis response system? A complexity science approach to organizational crises. Management Decision, 44, 892-907.

Parsons, C. M., \& Clair, J. A. (1989). Reframing Crisis Management Academy of Management Executive, 23(1), $59-76$.

Pauchant, \& Mitroff. (1992). Transforming the crisis-prone organization: Preventing individual, organizational and environmental tragedies. San Francisco: Jossey-Bass.

Pearson, \& Clair, J. A. (1998). Reframing crisis management. Academy of Management Review, 23, 59-76.

Pearson, \& Mitroff, I. I. (1993). From crisis prone to crisis prepared: A framework for crisis management. Academy of Management Executive, 48-59(7), 1.

Pforr, C., \& Hosie, P. J. (2008). Crisis Management in Tourism. Journal of Travel \& Tourism Marketing, 23(2-4). http://dx.doi.org/10.1300/J073v23n02_19

Racherla, P., \& Hu, C. (2009). A Framework for Knowledge-Based Crisis Management in the Hospitality and Tourism Industry. Cornell Hospitality Quarterly, 50(4), 561-577. http://dx.doi.org/10.1177/1938965509341633

Reilly, A. H. (1987). Are organizations ready for crisis? A managerial scorecard. Columbia Journal of World Business, 22(1), 79-88.

Roberts, K. H., \& Bea, G. (2001). Must accidents happen? Lessons from high reliability organizations. Academy of Management Executive, 15(3), 70-78.

Sayegh, L., Anthony, W. P., \& Perrewe, P. L. (2004a). Managerial decision making under crisis: The role of emotion in an intuitive decision process. Human Resource Management Review, 14, 179-199.

Sayegh, L., Anthony, W. P., \& Perrewe, P. L. (2004b). Managerial decision making under crisis: The role of emotion in an intuitive decision process. Human Resource Management Review, 14, 179-199

Smith. (1990). Beyond Contingency Planning: Towards a Model of Crisis Management. Organization and Environment, 4(4), 263-275 http://dx.doi.org/1177/108602669000400402

Smith. (1995). The dark side of excellence: Managing strategic failures. In J. Thompson (Ed.), Handbook of strategic management (pp. 161-191). London: Butterworth-Heinemann

Turner, B. (1976). The organizational and interorganizational development of disasters. Administrative Science Quarterly, 21, 378-397.

Wang, J., Hutchins, H. M., \& Garavan, T. N. (2009). Exploring the Strategic Role of Human Resource Development in Organizational Crisis Management. Human Resource Development Review, 8(1), 22-53. http://dx.doi.org/10.1177/1534484308330018

Wooten, L. P., \& James, E. H. (2008). Linking crisis management and leadership competencies: The role of human resource development. Advances in Developing Human Resources, 10, 352-379.

Yorks, L. (2005). Strategic human resource development. Mason, OH: South-Western Thomson. 


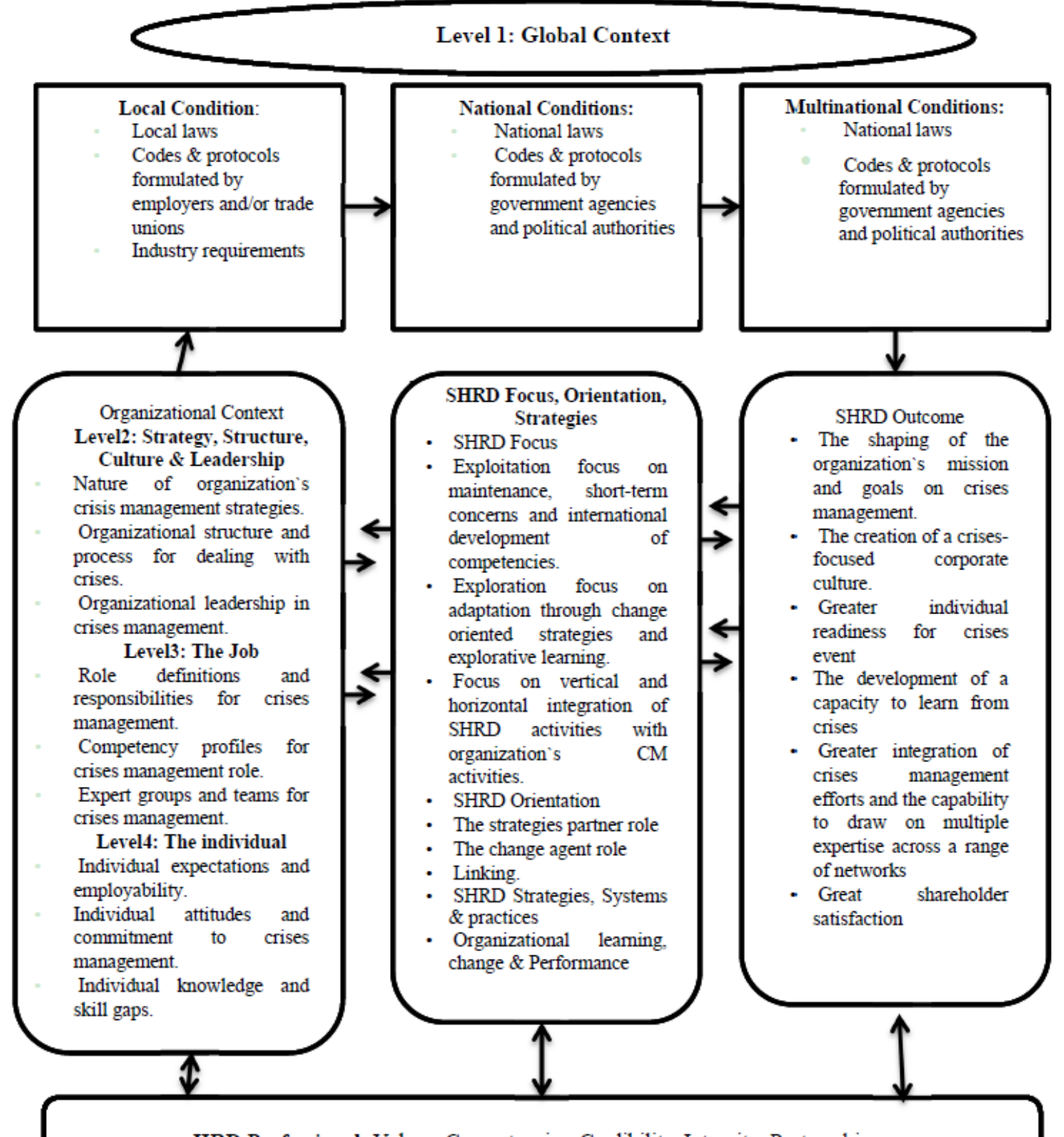

HRD Professional: Values, Competencies, Credibility, Integrity, Partnership

Figure 1. A conceptual framework of strategic human resources in organizational crisis management for food and beverage departments: adopted from Garavan (2007); Wang et al. (2009)

Figure 1 shows Garavan`s strategic human resource development in organizational crisis management framework. 